\title{
CIERRE DE LOS ACCESOS LAPAROSCÓPICOS CON LA AGUJA DE REVERDIN: UN NUEVO USO PARA UN VIEJO INSTRUMENTO
}

\author{
L.A. FARIÑA PÉREZ, E. ZUNGRI TELO \\ Servicio de Urología. Centro Médico POVISA. Vigo. Pontevedra.
}

Actas Urol Esp. 27 (2): 168-169, 2003

Señor Director:

El cierre de los accesos de 10 o más mm de diámetro es el último paso de toda intervención laparoscópica abdominal. A pesar de tener lugar en un momento de mayor relajación, es una parte importante del procedimiento y debe hacerse con precaución, para evitar complicaciones precoces y tardias como son las hernias intestinales y epiploicas y dehiscencias de las heridas.
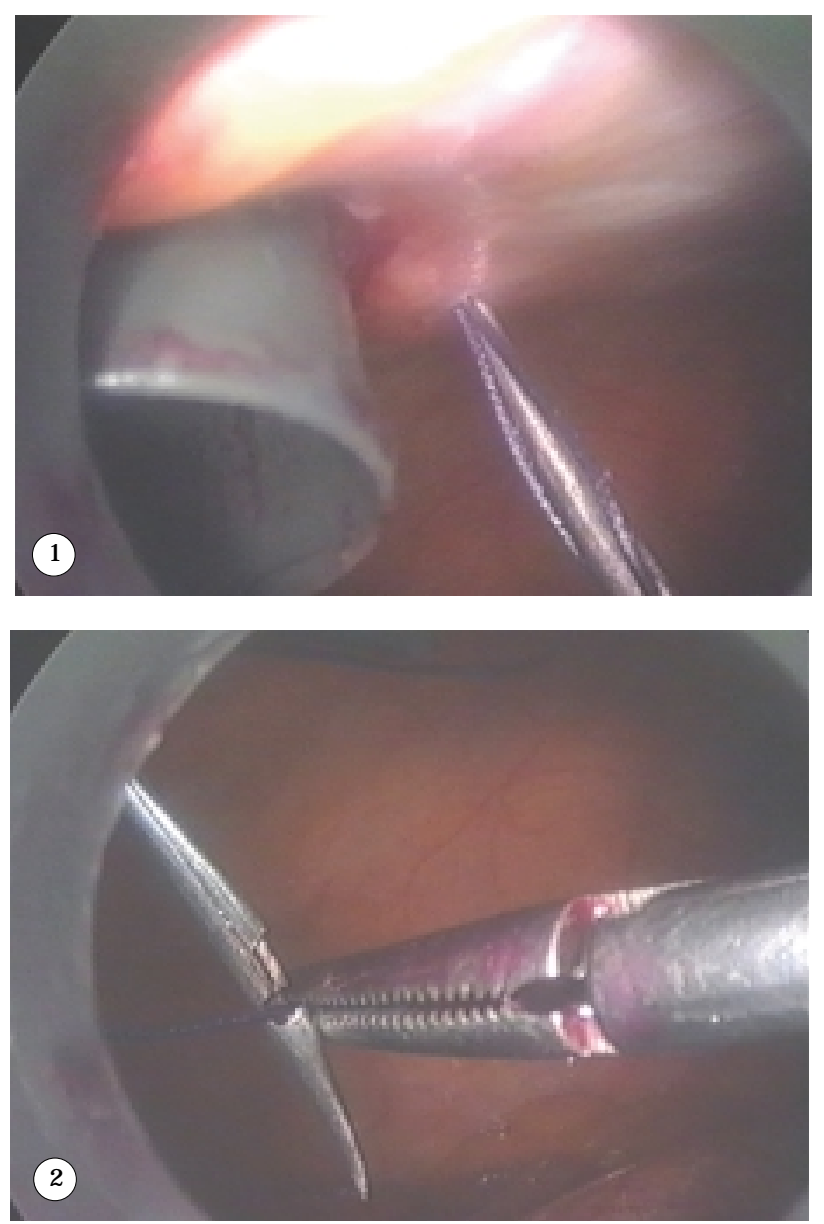

Las técnicas más usadas para el cierre de las aponeurosis son el cierre con visión directa mediante sutura montada sobre aguja (siempre difícil por el reducido campo de la incisión), y el cierre con instrumentos específicos, como el divulgado por Carter-Thomason, muy usado en EEUU $^{1,2}$. Nosotros usamos una aguja de Reverdin (Aesculap, Tuttlingen, referencia BM728R) con un proceder basado en el modo de actuar con la aguja
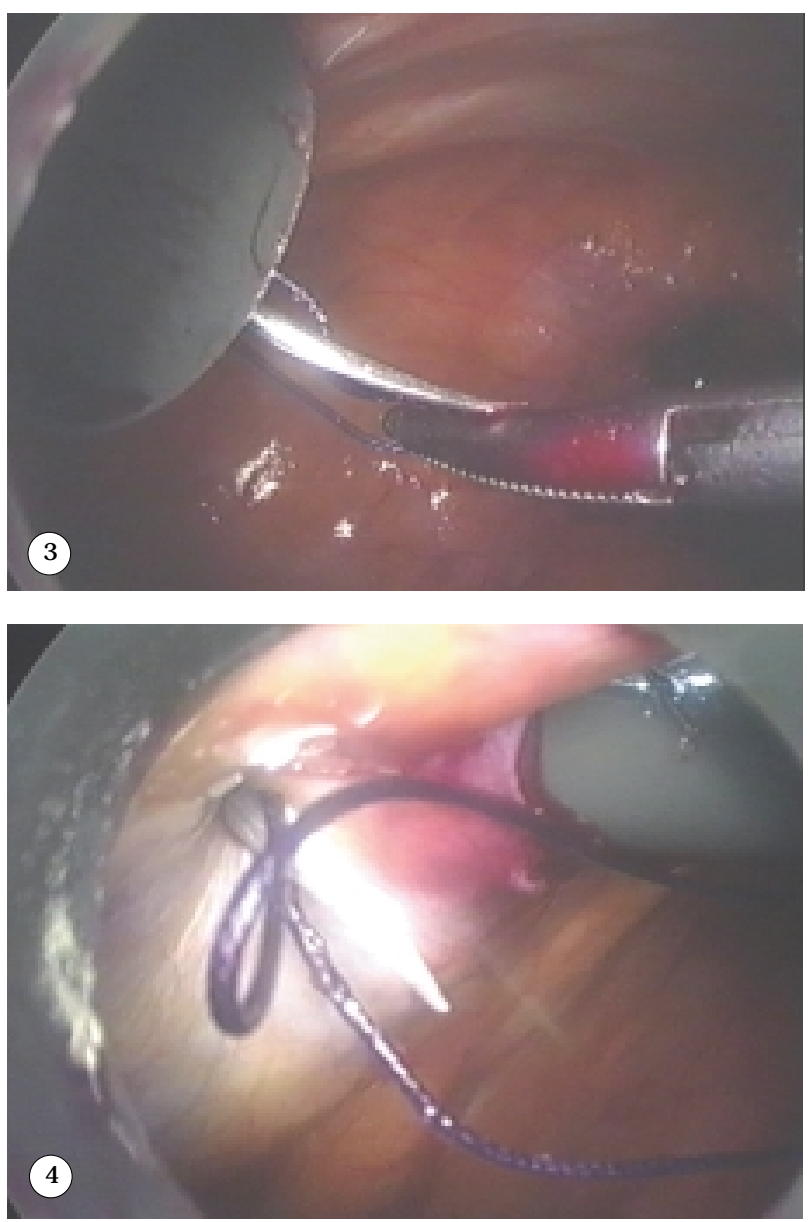
de Carter-Thomason, pero aprovechando las ventajas de que la aguja de Reverdin tiene más capacidad de penetrar las capas aponeuróticas y la prensión de la ligadura es muy segura una vez cerrada la aguja. La sucesión de pasos es la siguiente: la aguja paralela al trocar o a un dedo que ocluye el acceso, introduce una ligadura a un lado de la incisión (Fig. 1), que es recogida por una pinza laparoscópica desde un segundo trocar (Fig. 2) y entregada a continuación de nuevo a la aguja de Reverdin introducida por el otro lado de la incisión que se quiere cerrar (Figs. 3 y 4).

Basados en su uso en más de treinta intervenciones laparoscópicas, comprobamos que este procedimiento de cierre es muy sencillo y seguro, y revitalizamos un instrumento que desde que lo creara Jaques Reverdin (1842-1929, ayudante de
Félix Guyon en el Hospital Necker y profesor de cirugía en Ginebra), y hasta hace poco, era de uso habitual en el quirófano urológico.

\section{REFERENCIAS}

1. CARTER JE.: A new technique of fascial closure for laparoscopic incisions. J Laparoendosc Surg 1994; 4: 143-148.

2. ELASHRY OM, NAKADA SY, WOLF JS JR, FIGENSHAU RS, MCDOUGALL EM, CLAYMAN RV.:

Comparative clinical study of port-closure techniques following laparoscopic surgery. J Am Coll Surg 1996; 183: 335-344.

Dr. L.A. Fariña Pérez

Servicio de Urología. Centro Médico POVISA

Salamanca, 5

36211 Vigo (Pontevedra)

(Trabajo recibido el 16 de junio 2002) 